\title{
How to relax with a hamburger
}

A proposed new agency is a welcome first step towards a recovery of public trust in food. But an unsatisfactory history and unresolved questions necessitate continuing vigilance.

E arlier this week, a federal courthouse in Texas became the setting for a bizarre libel case. In the dock is the prominent and outspoken US talk-show host Oprah Winfrey, who told her audience during a live broadcast two years ago that concern about the possible presence of bovine spongiform encephalopathy (BSE) in US cattle had "stopped me cold from eating another hamburger". Challenging her, under relatively recent legislation passed in Texas and several other states, is a group of cattle ranchers who claim that Winfrey should be made to pay for the lost beef sales that followed her remark.

The outcome of the case will have both legal and political implications. At its heart is the same issue as that which the UK government has sought to address with its publication this week of proposals for a new Food Standards Agency (see page 313): how to encourage open public debate on food safety - including the most recent scientific findings on the topic, however tentative - without unfairly jeopardizing the interests of the producers.

The United Kingdom's recent BSE crisis, to which the creation of the new agency is partly a response, showed up in a dramatic fashion the extent to which the balance had got out of hand. Assurances of the safety of British beef in the late 1980s had more to do with preserving the economic interests of a lucrative industry than with solid science. Most pernicious, perhaps - as the recently announced public inquiry into the crisis is likely to reveal - is the way that these interests became directly reflected in the tight control exercised by the Ministry of Agriculture, Fisheries and Food (MAFF) over the analysis and interpretation of all veterinary data related to the epidemic of BSE as it swept through UK herds.

From this perspective, the arrangements for the new agency can be warmly welcomed as representing several important steps in the right direction. For example, the decision that it should be formally independent of government, and report to the Secretary of State for Health, embodies a principle that advice on food safety will now be prepared at arm's length from the interests of food producers. Equally welcome is the government's commitment to transparency: the commission's advice will be published, allowing the government's response to such advice to be closely scrutinized.

Still unresolved, however, is the question of how the agency's research agenda is to be set. Science will play a large role in its activities; the agency will have a research budget of about $£ 25$ million (US $\$ 40$ million) a year, and the government has promised that its assessments of food standards and safety will be "based on the best available scientific advice". This is certainly a necessary condition for rebuilding public confidence in the safety of British food products. There are already belated but encouraging signs of increasing input into the planning of food research from outside government, which will include representatives of the consumer. But these conditions will lead to success only if the agency has the right leadership. The US Food and Drug Administration provides a model in this respect at least, having been led in recent years by a political appointee who communicated well and who earned the trust of many political and public interests.

In setting up the Food Safety Agency, the UK government has set the stage for a bold experiment to tackle safety in a manner free (in principle) from the shibboleths of the past. Coinciding with other key decisions it faces, such as the future of the Institute of Food Research, as well as of MAFF's Central Science Laboratory, this experiment presents the government with a unique opportunity to forge a research base responsive to the long-term needs of food producers and consumers alike. But the new agency is still some years away. In the meantime, MAFF will need to be kept under close scrutiny.

\section{Halt the xeno-bandwagon}

Xenotransplantation's risks make a moratorium essential.

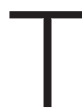
he momentum towards clinical trials of xenotransplantation is seemingly unstoppable, powered as it is by new prowess in genetic engineering that promises to pulverize the barrier of cross-species rejection, blended with an otherwise insatiable need for transplantable organs and multimillion dollar investment by biotechnology companies (see page 320).

But overcoming the huge obstacles to cross-species rejection is much further off than some biotechnology companies would like their investors and the public to believe. And premature trials carry the risk of creating new human diseases and pandemics (see page 327). Regrettably, the debate about xenotransplantation has amounted to a cacophony of messages from the various stakeholders about the potential risks and benefits. How can the public be expected to evaluate the possibilities when the experts themselves cannot agree?

Regulation of human cloning is politically easy, given its restricted benefits and the practical difficulties. Much greater polit- ical courage and enlightenment will be required to clarify the complex and pressing question of how best to regulate xenotransplantation, and this time in the face of predictable opposition from industrial and patient constituencies. Problems must not be papered over through compromises between the various conflicting interests, brokered by bureaucrats and expert committees within regulatory agencies, as has been amply shown by the bovine spongiform encephalopathy crisis, and the contamination of haemophiliacs with HIV during the 1980s.

A well-organized and informed public debate should precede any action by regulatory agencies. One model for the latter, offered on page 326, deserves studious attention. But until action is taken in this direction, politicians would do well to err on the side of caution, and agree on an international moratorium on clinical trials. What is at stake is not only risks to public health, but the real promise of xenotransplantation, which can only be compromised by undue haste. 